\title{
$\beta$-Lactone natural products and derivatives inactivate homoserine transacetylase, a target for antimicrobial agents
}

\author{
Gianfranco De Pascale ${ }^{1}$, Ishac Nazi ${ }^{1}$, Paul HM Harrison ${ }^{2}$ and Gerard D Wright ${ }^{1}$
}

Homoserine transacetylase (HTA) catalyzes the transfer of an acetyl group from acetyl-CoA to the hydroxyl group of homoserine. This is the first committed step in the biosynthesis of methionine (Met) from aspartic acid in many fungi, Gram-positive and some Gram-negative bacteria. The enzyme is absent in higher eukaryotes and is important for microorganism growth in Met-poor environments, such as blood serum, making HTA an attractive target for new antimicrobial agents. HTA catalyzes acetyl transfer via a double displacement mechanism facilitated by a classic Ser-His-Asp catalytic triad located at the bottom of a narrow actives site tunnel. We explored the inhibitory activity of several $\beta$-lactones to block the activity of HTA. In particular, the natural product ebelactone $A$, a $\beta$-lactone with a hydrophobic tail was found to be a potent inactivator of HTA from Haemophilus influenzae. Synthetic analogs of ebelactone A demonstrated improved inactivation characteristics. Covalent modification of HTA was confirmed by mass spectrometry, and peptide mapping identified Ser143 as the modified residue, consistent with the known structure and mechanism of the enzyme. These results demonstrate that $\beta$-lactone inhibitors are excellent biochemical probes of HTA and potential leads for new antimicrobial agents.

The Journal of Antibiotics (2011) 64, 483-487; doi:10.1038/ja.2011.37; published online 27 April 2011

Keywords: antimicrobials; homoserine transacetylase; lactones

\section{INTRODUCTION}

The last decade has witnessed an increased interest in the aspartate (Asp) biosynthetic pathway in bacteria and fungi (Figure 1). ${ }^{1-4}$ This pathway uses several enzymes to produce the essential amino acids methionine (Met), Thr and Ile, which are not produced in mammals. ${ }^{5}$ The absence of this pathway in mammals makes it an attractive target for antimicrobial drug discovery. Small molecule inhibitors have been discovered and used as probes of the catalytic and biochemical functions of the different enzymes of this pathway including cystathionine $\beta$-lyase, ${ }^{6}$ homoserine transacetylase (HTA), ${ }^{7-11}$ Met synthase $(\text { MET6) })^{2}$ and homoserine dehydrogenase (HOM6).,12-14 Moreover, gene disruption methods have identified the importance of these enzymes in pathogenesis in several animal models of virulence. ${ }^{1,2,4,15-17}$

One key enzyme in the Asp pathway is HTA, which catalyzes the transfer of an acetyl group from acetyl-CoA to the hydroxyl group of homoserine (Figure 1). ${ }^{18}$ This enzyme catalyzes the first committed step in the biosynthesis of Met from aspartic acid. ${ }^{5}$ Extensive biochemical and structural studies have been performed on HTA from the fission yeast Schizosaccharomyces pombe and the Gramnegative bacterial pathogen Haemophilus influenzae.,18 Genetic studies in bacteria and yeast have shown that deletion of the gene that encodes for HTA is lethal in minimal media and Met supplementation is required for cell viability. ${ }^{8,9,19-21}$ Furthermore, the gene encoding HTA, MET2, has been found to be required for virulence in the human pathogen Cryptococcus neoformans. ${ }^{8}$ These genetic studies suggest that HTA is a good target for new antibiotics.

HTA promotes acyl transfer via a Ping-Pong, or double displacement, mechanism facilitated by a catalytic triad comprised of Ser143, His337 and Asp304 (H. influenzae numbering). The Ser143 hydroxyl is activated for nucleophilic attack on the carbonyl center of acetyl-CoA by His337. This results in the covalent modification of the enzyme and the release of CoA. The second step of the mechanism involves nucleophilic attack by the hydroxyl group of the homoserine substrate on the labile ester bond formed between the enzyme and the acetyl group. Finally, the acetylated amino acid is released and the enzyme is ready for another round of catalysis.

Our studies indicate that HTA is an important enzyme for organisms in Met-poor environments, such as serum. ${ }^{22}$ We reasoned that inhibition of this enzyme would be deleterious to pathogens, as Met is involved in several biochemical processes. Several enzyme inhibitors such as the $\beta$-lactams of the penicillin and cephalosporin class work

\footnotetext{
${ }^{1}$ Michael G DeGroote Institute for Infectious Disease Research, Department of Biochemistry and Biomedical Sciences, McMaster University, Hamilton, Ontario, Canada and 2Department of Chemistry and Chemical Biology, McMaster University, Hamilton, Ontario, Canada

Correspondence: Professor GD Wright, Michael G DeGroote Institute for Infectious Disease Research, Department of Biochemistry and Biomedical Sciences, McMaster University, 1200 Main Street W, Hamilton, Ontario, Canada L8N $3 Z 5$.

E-mail: wrightge@mcmaster.ca
}

Received 11 February 2011; revised 21 March 2011; accepted 22 March 2011; published online 27 April 2011 

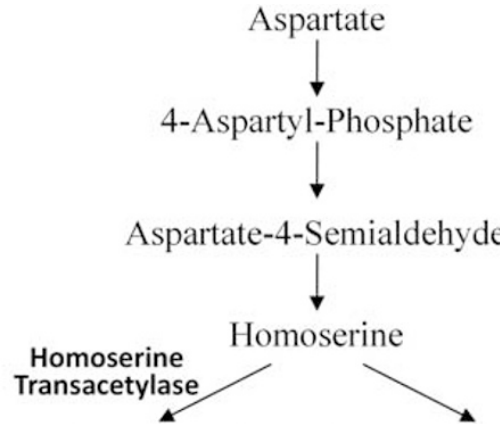

O-Acetyl-Homoserine

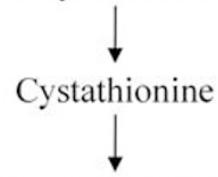

Homocysteine<smiles>[3H][13CH3]</smiles>

Methionine
O-Phospho-Homoserine

Threonine

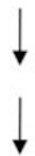

Isoleucine

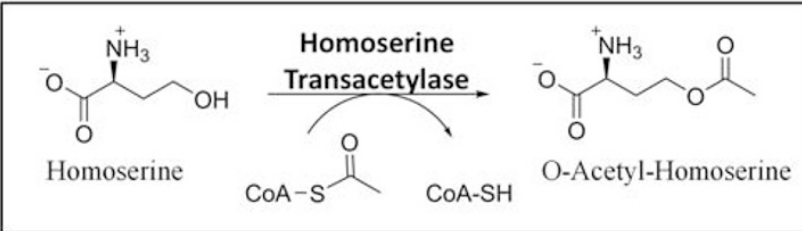

Figure 1 Microbial aspartate biosynthetic pathway leads to the production of Met, Thr and Ile.

on the basis of enzyme inactivation via covalent modification of active site serine (Ser). ${ }^{23}$ A similar strategy targeting HTA could generate novel antimicrobial agents, which are sorely needed in the face of drug resistance and the emergence of new pathogens. The three-dimensional structure of HTA reveals an elongated substrate-binding tunnel that leads to the nucleophile Ser in the active site involved in catalysis (Figure 2). ${ }^{7}$ Potential inactivators that take advantage of both modification of the active site Ser and the substrate-binding tunnel should be good probes of HTA function and potential leads for antimicrobial agents. We describe the inactivation of $H$. influenzae HTA by natural product and synthetic $\beta$-lactones and use these to biochemically confirm that Ser143 is the active site nucleophile and evaluate their antibiotic activity.

\section{MATERIALS AND METHODS}

\section{HTA expression and purification}

An overexpression plasmid with the MET2 gene encoding HTA from H. influenzae $\left(\mathrm{HTA}_{\mathrm{Hin}}\right.$ ) was cloned into the pET28 vector (Novagen; Merck KGaA, Darmstadt, Germany) at the Nde I and Hind III restriction enzyme sites. ${ }^{7}$ The construct was introduced into Escherichia coli BL21 (DE3) allowing for the expression of $\mathrm{HTA}_{\mathrm{Hin}}$ with an N-terminal hexa-histidine tag.

E. coli BL21 (DE3)/HTA $\mathrm{Hin}_{\text {in }}$ was cultured in 11 of Luria-Bertani broth supplemented with $50 \mu \mathrm{g} \mathrm{ml}^{-1}$ kanamycin to an optical density $\left(\mathrm{OD}_{600}\right)$ of 0.6 at $37^{\circ} \mathrm{C}$. Isopropyl $\beta$-D-thiogalactopyranoside was added to a final concentration of $1 \mathrm{~mm}$, followed by overnight incubation at $16^{\circ} \mathrm{C}$ in an orbital shaker. The cultures were harvested by centrifugation at $8000 \times g$ for $10 \mathrm{~min}$ and resuspended in a final volume of $15 \mathrm{ml}$ of lysis buffer (50 mm 4-(2-hydroxyethyl)-1-piperazineethanesulfonic acid (HEPES; pH 8.0), $500 \mathrm{~mm} \mathrm{NaCl}, 10 \mathrm{~mm}$ imidazole, $5 \%$ glycerol and one complete protease inhibitor cocktail tablet (Roche, Laval, QC, Canada)). The cells were disrupted by three passes through a French pressure cell at 10000 p.s.i. and the cell debris was removed by centrifugation at $50000 \mathrm{~g}$ for

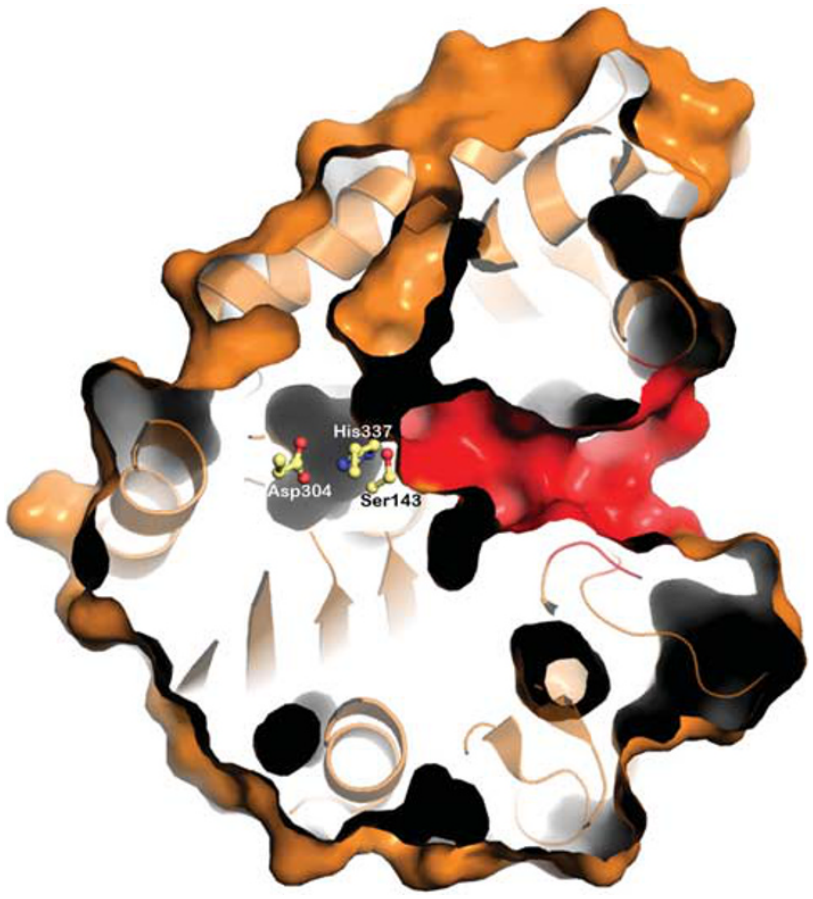

Figure 2 Cross section of $\mathrm{HTA}_{H i n}$ highlighting the active site tunnel (red) and catalytic triad (represented as sticks). ${ }^{7}$

$30 \mathrm{~min}$. The supernatant was applied onto a $5 \mathrm{ml} \mathrm{Ni}$ Sepharose columns (GE Healthcare, Baie d'Urfe, QC, Canada) which was then washed with $25 \mathrm{ml}$ of buffer A (50 mm HEPES ( $\mathrm{pH} 8.0$ ), $500 \mathrm{~mm} \mathrm{NaCl}$ and $20 \mathrm{~mm}$ imidazole). Protein was eluted by using an increasing gradient of imidazole to a final concentration of $500 \mathrm{~mm}$ of imidazole in $50 \mathrm{~mm}$ HEPES ( $\mathrm{pH} \mathrm{8.0)}$ and $500 \mathrm{~mm} \mathrm{NaCl}$ over a period of $30 \mathrm{~min}$. Fractions containing recombinant $\mathrm{HTA}_{\mathrm{Hin}}$ were determined by sodium dodecylsulfate-polyacrylamide gel electrophoresis and the appropriate fractions were pooled for buffer exchange to $50 \mathrm{~mm}$ HEPES (pH 8.0), $250 \mathrm{~mm}$ $\mathrm{NaCl}$ and $2 \mathrm{mM} \mathrm{MgCl}_{2}$ via dialysis overnight at $4{ }^{\circ} \mathrm{C}$.

\section{$\beta$-Lactones}

Compounds 1 and 2 were synthesized as previously described..$^{24,25}$ Ebelactone A was purchased from Sigma (St Louis, MO, USA). F-244 (also known as hymeglusin, 1233A and L-659, 699) was purchased from Cedarlane (Burlington, ON, Canada).

\section{HTA $_{\text {Hin }}$ enzymatic assay}

Enzyme assays were performed in a SpectraMAX Plus (Molecular Devices, Sunnyvale, CA, USA) spectrophotometer using 384-well flat-bottom polystyrene microtiter plates (VWR, Mississauga, ON, Canada). The $\mathrm{HTA}_{\text {Hin }}$ activity was determined by monitoring the production of free CoA due to the increase in absorbance at $324 \mathrm{~nm}$ on titration with $4,4^{\prime}$-dithiodipyridine (4,4'-dithiodipyridine $\left.\varepsilon_{324 \mathrm{~nm}}=19800 \mathrm{M}^{-1} \mathrm{~cm}^{-1}\right)$. Assays were performed in $50 \mathrm{~mm}$ HEPES (pH 8.0) containing $0.001 \%$ Tween-20, $200 \mu \mathrm{M} L$-Hse, 2 mм 4,4'-dithiodipyridine and $300 \mu \mathrm{m}$ acetyl-CoA. The reaction was started by the addition $(5 \mu \mathrm{l})$ of enzyme that was preincubated with the compounds. The preincubation mixture was in $50 \mathrm{~mm}$ HEPES ( $\mathrm{pH} 8.0$ ) containing $8 \mu \mathrm{g} \mathrm{ml}^{-1} \mathrm{HTA}_{\text {Hin }}$, $100 \mu \mathrm{M}$ inhibitor and 10\% dimethyl sulfoxide. As compound 1 and 2 are racemic mixtures (1:1), the concentrations were corrected assuming that only one chiral isomer is the active compound. The kinetic constants were determined using Kitz-Wilson plots ( $1 / k_{\text {obs }}$ versus $\left.1 /[\mathrm{I}]\right)$.

\section{Time-dependent inactivation of HTA}

$\mathrm{HTA}_{\text {Hin }}\left(8 \mu \mathrm{g} \mathrm{ml}^{-1}\right)$ inactivation experiments were carried out in $50 \mathrm{~mm}$ HEPES ( $\mathrm{pH}$ 7.5) with varying concentrations of the compounds in dimethyl sulfoxide 
$(5 \% \mathrm{v} / \mathrm{v})$ in a final volume of $200 \mu \mathrm{l}$. Samples $(20 \mu \mathrm{l})$ were withdrawn from the reaction at different times and the activity of the enzyme was monitored at $324 \mathrm{~nm}$ in $180 \mu \mathrm{l}$ of the assay mixture containing $50 \mathrm{~mm}$ HEPES ( $\mathrm{pH} 7.5$ ), $0.3 \mathrm{~mm}$ homoserine, $0.2 \mathrm{~mm}$ acetyl-CoA, $2.0 \mathrm{~mm} 4,4^{\prime}$-dithiodipyridine and $0.001 \% \mathrm{v} / \mathrm{v}$ Tween- 20 .

\section{HTA $_{H i n}$ inactivation for acyl-enzyme detection}

Large-scale inactivation of $\mathrm{HTA}_{\mathrm{Hin}}$ was carried out to determine the modification of the enzyme by the formation of an acyl-enzyme moiety using mass spectrometry (MS). $\mathrm{HTA}_{\text {Hin }}\left(0.64 \mu \mathrm{g} \mu \mathrm{l}^{-1}\right)$ was mixed with $1.25 \mathrm{~mm}$ of compound $(5 \% \mathrm{v} / \mathrm{v})$ and $50 \mathrm{~mm}$ HEPES (pH 7.5). A sample of the reaction $1 \mu \mathrm{l}$ (after 100fold dilution) was monitored for activity of the enzyme. Liquid chromatography electrospray ionization tandem MS data were obtained for $50 \mu \mathrm{l}$ of the reaction mixture using an Agilent 1100 Series LC (Agilent Technologies, Mississauga, ON, Canada) and a QTRAP mass spectrometer (AB SCIEX, Foster City, CA, USA).

The protein cleavage and MS/MS analysis were performed at McMaster Regional Centre for Mass Spectrometry. The previously described samples were incubated with trypsin and chymotrypsin (Promega, Madison, WI, USA) in $50 \mathrm{~mm} \mathrm{NH} \mathrm{NHCO}_{3} 10 \% \mathrm{v} / \mathrm{v}$ acetonitrile overnight at $37^{\circ} \mathrm{C}$. The reaction was stopped by the addition of $1 \%$ of glacial acetic acid to get $\mathrm{pH} 2-4$. Subsequently, the samples were applied on a ZipTip C18 (Millipore, Billerica, $\mathrm{MA}$, USA) and eluted with $10 \mu \mathrm{l} \mathrm{CH}_{3} \mathrm{CN} / \mathrm{H}_{2} \mathrm{O}(50 / 50)$ containing $0.2 \%$ acetic acid. The samples were analyzed on a Micromass Global Q-TOF Ultima mass spectrometer with Nano-ESI source (Waters Corporation, Milford, MA, USA).

\section{Site-directed mutagenesis of HTA}

To investigate the role Ser143 of $\mathrm{HTA}_{H i n}$, the site-specific mutant Ser163Ala, was prepared using the QuikChange II Site-Directed Mutagenesis Kit (Agilent Technologies, Stratagene Products Division, La Jolla, CA, USA). The oligonucleotides used for the construction of this mutant were $5^{\prime}$-CGATTATTGGTGG AGCTTTTGGCGGCATGCAAGCG- $3^{\prime}$ and $5^{\prime}$-CGCTTGCATGCCGCCAAAAG CTCCACCAATAATCG-3'. The expression, purification, enzyme activity and MS analysis of this mutant followed the procedure outlined above for the wildtype enzyme.

\section{In vitro antimicrobial susceptibility testing}

The antimicrobial activity of all compounds was tested by broth microdilution methods according to the Clinical Laboratory Standards Institute guidelines for using both bacterial and fungal test organisms in synthetic complete medium with and without Met. The tested bacterial and yeast strains were: $H$. influenzae ATCC 49247, Bacillus subtilis 168, Micrococcus luteus, E. coli, Candida albicans, Saccharomyces cerevisiae, S. pombe and Aspergillus fumigatus. Only the strains that exhibited susceptibility to the $\beta$-lactone compounds are reported in the results section. Minimal inhibitory concentrations of the compounds were determined in triplicate over a test range of $0.12-128 \mu \mathrm{g} \mathrm{ml}^{-1}$.

\section{RESULTS}

\section{$\beta$-Lactone inactivation of $\mathrm{HTA}_{\mathrm{Hin}}$}

The natural products F-244, an inhibitor of HMG-CoA synthase ${ }^{26}$ produced by the ascomycete Scopulariopsis sp., and ebelactone A, a potent esterase inhibitor produced by Streptomyces sp. MG7-G1, ${ }^{27-29}$ are $\beta$-lactones that incorporate a hydrophobic tail (Figure 3 ) and therefore are candidates as potential inhibitors of HTA. F-244 showed little in vitro $\mathrm{HTA}_{\text {Hin }}$ inhibition; however ebelactone A did block $\mathrm{HTA}_{\text {Hin }}$ activity. We therefore tested two synthetic analogs, compounds 1 and 2, for their inhibitory activity against $\mathrm{HTA}_{H i n}$. These compounds are a C3-unsubstituted and a C3-methyl substituted oxetan-2-one with different alkyl chain length (Figure 3a). ${ }^{24}$ These promising initial results were followed up with rigorous determination of inhibition mechanism and kinetics.

The inhibition of $\mathrm{HTA}_{\mathrm{Hin}}$ was assayed at several incubation times between 5 and $200 \mathrm{~min}$. In all cases, time-dependent inhibition was observed, consistent with enzyme inactivation. The dissociation constant $K_{i}$ and the first order rate of inactivation, $k_{\text {inact }}$, were determined<smiles>CCCCCCC[C@H]1OC(=O)C1C</smiles>

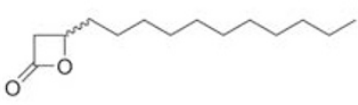

2

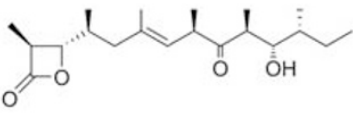

Ebelactone A

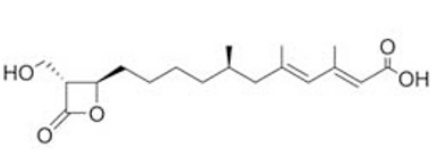

F-244
1

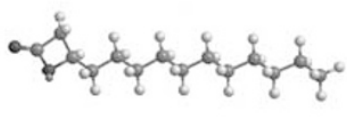

2

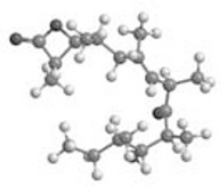

Ebelactone A

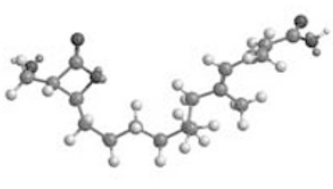

F-244

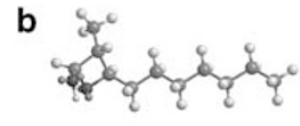

Figure 3 Structures (a) and three-dimensional models (b) of the HTA ${ }_{\text {Hin }}$ inhibitors. Compound $\mathbf{1}$ is a trans-disubstituted $\beta$-lactone that is racemic, $\mathbf{2}$ is a racemate. The three-dimensional models were obtained using geometry minimization with standard MM2. ${ }^{34}$

Table 1 Inhibition constants of $\beta$-lactones on HTA Hin $_{\text {-lan }}$

\begin{tabular}{lcc}
\hline Compound & $K_{i}(\mu \mathrm{M})$ & $k_{\text {inact }}\left(\mathrm{min}^{-1}\right)$ \\
\hline $\mathbf{1}$ & $10 \pm 1^{\mathrm{a}}$ & $0.09 \pm 0.01$ \\
$\mathbf{2}$ & $84 \pm 8^{\mathrm{a}}$ & $0.10 \pm 0.01$ \\
Ebelactone A & $203 \pm 12$ & $0.011 \pm 0.001$ \\
\hline
\end{tabular}

Abbreviation: HTA, homoserine transacetylase.

aWe assume that only one enantiomer is active.

using an increasing amount of each compound (between 2 and $500 \mu \mathrm{M}$; Table 1).

To evaluate the reversibility of inhibition, the $\mathrm{HTA}_{\mathrm{Hin}}$ activity was assayed following the removal of unreacted compounds from the incubation of enzyme with inhibitor. $\mathrm{HTA}_{\mathrm{Hin}}$ was first incubated with $200 \mu \mathrm{M}$ of compound in $50 \mathrm{~mm}$ HEPES buffer ( $\mathrm{pH}$ 8.0) for $15 \mathrm{~min}$. The compound was then removed by using a microconcentrator column with a $10000 \mathrm{Da}$ molecular weight cutoff (Amicon Ultra 10, Millipore, Billerica, MA, USA). The acetyltransferase activity was assessed at different time intervals between 0 and $18 \mathrm{~h}$. For all the compounds tested, no recovery of activity was observed.

\section{Determination of site of inactivation of $\mathrm{HTA}_{\mathrm{Hin}}$}

The formation of a covalent adduct between ebelactone A or compound 1 and $\mathrm{HTA}_{H i n}$ was confirmed by MS. The protein was incubated for $180 \mathrm{~min}$ with each inhibitor. In each case, an increase in the mass of $\mathrm{HTA}_{\mathrm{Hin}}$ was observed: $338.45 \mathrm{Da}$ and $184.14 \mathrm{Da}$ for enzyme incubated with ebelactone $\mathrm{A}$ and $\mathbf{1}$, respectively. These increments in $\mathrm{HTA}_{\mathrm{Hin}}$ mass correspond to the addition of one molecule of inhibitor per molecule of enzyme. Using trypsin/chymo- 
Table 2 Predicted and observed mass for the ALLGGSF peptide ions of $\mathrm{HTA}_{\mathrm{Hin}}$ in presence and absence of inhibitors

\begin{tabular}{lllll}
\hline & & \multicolumn{3}{c}{ Predicted mass (Da) } \\
\cline { 3 - 5 } Ion & Sequence & HTA & HTA+EA & $H T A+1$ \\
\hline B2 & AL & 182.13 & $182.13^{\mathrm{a}}$ & 182.13 \\
B3 & ALL & 298.21 & $298.21^{\mathrm{a}}$ & 298.21 \\
B4 & ALLG & 355.23 & $355.23^{\mathrm{a}}$ & $355.23^{\mathrm{a}}$ \\
B5 & ALLGG & 412.25 & $412.25^{\mathrm{a}}$ & $412.25^{\mathrm{a}}$ \\
B6 & ALLGGS & 499.26 & $837.71^{\mathrm{a}}$ & $683.40^{\mathrm{a}}$ \\
Y1 & F & 166.09 & $166.09^{\mathrm{a}}$ & 166.09 \\
Y2 & SF & 253.12 & $591.57^{\mathrm{a}}$ & $437.26^{\mathrm{a}}$ \\
Y3 & GSF & 310.14 & $648.59^{\mathrm{a}}$ & $494.28^{\mathrm{a}}$ \\
Y4 & GGSF & 367.16 & $705.61^{\mathrm{a}}$ & $551.30^{\mathrm{a}}$ \\
Y5 & LGGSF & 480.24 & $818.69^{\mathrm{a}}$ & $664.38^{\mathrm{a}}$ \\
\hline
\end{tabular}

Abbreviations: 1, compound 1; EA, ebelactone A; HTA, homoserine transacetylase. In bold are highlighted the ions of peptides containing Ser143.

a Observed mass: ebelactone A molecular weight, $338.48 \mathrm{Da}$; compound 1 molecular weight, 184.14 Da.

trypsin hydrolysis of $\mathrm{HTA}_{\mathrm{Hin}}$, we identified a peptide that includes the Ser143 in the active site, ALLGGSF (residues 138-144). HTA Hin was next incubated with each inhibitor then cleaved with trypsin/chymotrypsin followed by mass spectrometric peptide mapping (Table 2). For all the $\mathrm{B}$ and $\mathrm{Y}$ ions of the peptides that include Ser143, an increment in mass of one molecule of inhibitor was observed (Table 2).

To further prove the essential role of Ser143 in the acetyltransferase activity and its inhibition by ebelactone A and 1, an $\mathrm{HTA}_{\mathrm{Hin}}$ Ser143Ala mutant was generated. The mutant did not show any acetyltransferase activity. Furthermore, incubation of $\mathrm{HTA}_{\mathrm{Hin}}$ Ser143Ala with ebelactone $\mathrm{A}$ and $\mathbf{1}$ did not generate an enzyme-inhibitor adduct as assessed by MS.

\section{Antimicrobial activity of the active compounds}

The three compounds were tested for their inhibitory activity against several bacterial and yeast strains by the broth microdilution method in the presence and absence of Met. An inhibitor of HTA would block the growth of these microorganisms in Met-deficient media; supplementation of Met would restore growth. None of the compounds showed antimicrobial activity against $H$. influenzae ATCC 49247. Compound 2 showed antibacterial activity versus B. subtilis 168 with a minimal inhibitory concentration of $16 \mu \mathrm{g} \mathrm{ml}^{-1}$ in both the presence and absence of Met. C. albicans growth was inhibited by ebelactone A (minimal inhibitory concentration of $64 \mu \mathrm{g} \mathrm{ml}^{-1}$ in presence and absence of Met) and compound 1 (minimal inhibitory concentration of $32 \mu \mathrm{g} \mathrm{ml}^{-1}$ in presence of Met and $8 \mu \mathrm{g} \mathrm{ml}^{-1}$ in media lacking of Met).

\section{DISCUSSION}

Methionine is essential for cell growth. It is required for protein synthesis and it is also the precursor for $S$-adenosylmethionine, the main biological methyl donor. In plants, fungi and bacteria Met can be biosynthesized, but mammals are unable to produce it and require a dietary supply. Therefore, the microbial enzymes involved in the biosynthesis of this essential amino acid are good targets for new antibiotic and antifungal compounds. A promising target in this pathway is HTA, which catalyzes the first committed step in the biosynthesis of Met from Asp. HTA is present in several pathogenic bacterial species such as $H$. influenzae, ${ }^{7,18,30}$ Pseudomonas aeruginosa, Mycobacterium tuberculosis, ${ }^{31}$ Leptospira meyeri ${ }^{32}$ and most fungi. ${ }^{8,9,33}$

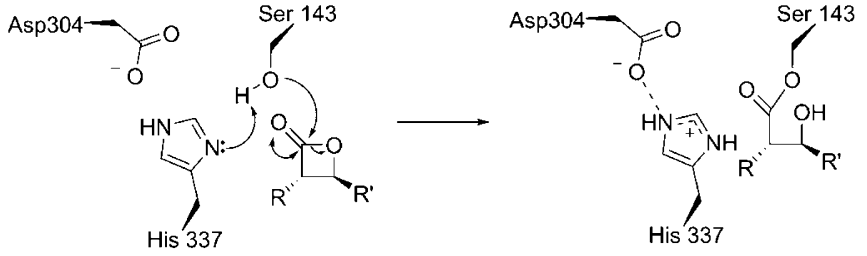

Figure 4 Proposed mechanism of inactivation of HTA by $\beta$-lactones.

HTA uses a classic Ser/His/Asp catalytic triad to promote transfer of the acetyl group from acetyl-CoA to homoserine. ${ }^{18}$ Several studies in the past have shown a time-dependent inhibition of $\beta$-lactam and $\beta$-lactone compounds against Ser/His/Asp catalytic triad enzymes such as penicillin-binding proteins, ${ }^{34} \beta$-lactamases ${ }^{23,35}$ and several Ser proteases. ${ }^{36-38}$ On the basis of this precedent for other Ser/His/Asp catalytic triad enzymes, we reasoned that HTA might be inhibited by similar compounds that have the potential to form a covalent bond with the catalytic Ser (Figure 4). Furthermore, the active site and substrate binding geometry of HTA is unique. The catalytic Ser is at the 'bottom' of a substrate-binding tunnel that can accommodate the acetyl-pantetheine arm of acetyl-CoA and the hydroxy ethyl group of homoserine (Figure 2). We therefore tested a series of $\beta$-lactones with acyl chains that could sample this substrate-binding site using the enzyme from $H$. influenzae as an in vitro target. The fungal secondary metabolite F-244 had no affinity for $\mathrm{HTA}_{\mathrm{Hin}}$, but the bacterial natural product ebelactone $\mathrm{A}$ was an inactivator. Two synthetic ebelactone analogs, compounds 1 and 2, of ebelactone A also showed timedependent enzyme inactivation activity, with improved $\mathrm{K}_{\mathrm{i}}$ and $k_{\text {inact }}$.

The different stereochemistry of F-244 compared with the other $\beta$-lactones tested (F-244 is $2 R, 3 R$ whereas all the other $\beta$-lactones are $2 S, 3 S)$ may be the reason for lack of inhibition by this compound; as reported for $\beta$-lactone DU-6622, where the pancreatic lipase and HMG-CoA synthase were inhibited by specific chiral isomers. ${ }^{39,40}$ The differences in $k_{\text {inact }}$ between ebelactone $\mathrm{A}$ and compound $\mathbf{1}$ and 2 may reflect differences in the three-dimensional structures of these compounds. Ebelactone A can adopt a C-shape conformation, as shown in the predicted model (Figure $3 \mathrm{~b}$ ) and in the recent X-ray structure of the compound. ${ }^{41}$ Furthermore, the methyl groups on the alkyl chain could interfere with entry to the tunnel and/or the ketone and alcohol groups could make unfavorable interactions with the hydrophobic tunnel wall. Instead, compounds $\mathbf{1}$ and $\mathbf{2}$ are predicted to adopt a more linear conformation (Figure $3 b$ ), which could facilitate their access through the tunnel that leads to the active site. The $K_{i}$ of 1 is between 10- and 20-fold lower than the $K_{i}$ of ebelactone A and 2 (Table 1). This difference could be the result of the alkyl chain length: the smaller alkyl chain of compound $\mathbf{1}(\sim 12 \AA)$ will fully fit in the active site tunnel of $\mathrm{HTA}_{H \text { in }}(\sim 14 \AA)$. Compound $2(\sim 17.5 \AA)$ on the other hand, will not be able to entirely fit in the hydrophobic $\mathrm{HTA}_{\mathrm{Hin}}$ active site tunnel and the protruding alkyl chain may make unfavorable interactions with the enzyme and/or aqueous medium.

The penicillin-binding proteins are irreversibly inhibited by $\beta$-lactams via the acylation of the nucleophilic Ser in the active site. ${ }^{23}$ In contrast, $\beta$-lactams are reversible inhibitors of some Ser proteases. ${ }^{37}$ In this case, the protease cleaves the $\beta$-lactams and the cleaved products compete with the substrate. $\mathrm{HTA}_{H i n}$ is irreversibly inhibited by the three $\beta$-lactone compounds. Saturation of $\mathrm{HTA}_{\mathrm{Hin}}$ with all the compounds followed by filtration of the excess inhibitor did not result in the recovery of activity. The irreversible nature of inhibition by ebelactone A and $\mathbf{1}$ was also confirmed by the formation of protein-inhibitor adducts, which were detected by MS. Tandem MS 
experiments with the peptide fragment containing Ser143 unequivocally demonstrated covalent adduct formation with $\mathrm{HTA}_{H i n}$ (Figure 4). The active role of Ser143 was also confirmed by the inability of the Ser143Ala mutant to bind the inhibitor and to carry out the acetylation of L-homoserine.

In vivo studies showed inhibitory activities of all three compounds against $B$. subtilis or $C$. albicans. The lack of activity of these compounds versus $H$. influenzae could be attributed to several factors including the impermeant outer membrane of Gram-negative bacteria, active efflux or drug inactivation. The inhibitory activity of ebelactone A and 2 versus C. albicans and B. subtilis, respectively, were not reversed by addition of excess Met and therefore cannot be unambiguously attributed to inhibition of HTA. On the other hand, the inhibition of $C$. albicans growth by compound 2 was partially rescued by the addition of Met, suggesting that HTA is an in vivo target of this compound and chemically validates HTA as an antibiotic target.

Our work clearly shows that $\beta$-lactones are inhibitors of HTA. They inactivate the transacetylase activity of homoserine by irreversible acylation of Ser143 in the active site of the enzyme. Structure-activity relationship studies showed that $\beta$-lactones with a shorter alkyl chain and an extended linear conformation are better inhibitors. Modification of this scaffold can lead to more potent compounds, providing us with novel antimicrobial agents urgently needed to fight the increasing number of antibiotic resistant pathogens.

\section{ACKNOWLEDGEMENTS}

This work was supported by the Canadian Institutes of Health Research (grant FRN-79488 to GDW) and the Canada Research Chairs program (support to GDW). We also thank the Natural Sciences and Engineering Research Council of Canada (NSERC) for their support (to PH). We thank Dr Jiaxi Wang and Dr M Kirk Green of the McMaster Regional Centre for Mass Spectrometry for mass spectral analyses and Dr Mariya Morar for assistance in preparing Figure 2.

1 Ejim, L. J. et al. Cystathionine beta-lyase is important for virulence of Salmonella enterica serovar Typhimurium. Infect. Immun. 72, 3310-3314 (2004).

2 Pascon, R. C., Ganous, T. M., Kingsbury, J. M., Cox, G. M. \& McCusker, J. H. Cryptococcus neoformans methionine synthase: expression analysis and requirement for virulence. Microbiology 150(Pt 9), 3013-3023 (2004).

3 Yamaguchi, H. et al. RI-331, a new antifungal antibiotic. Ann. NY Acad. Sci. 544, 188-190 (1988)

4 Yang, Z., Pascon, R. C., Alspaugh, A., Cox, G. M. \& McCusker, J. H. Molecular and genetic analysis of the Cryptococcus neoformans MET3 gene and a met3 mutant. Microbiology 148(Pt 8), 2617-2625 (2002).

5 Umbarger, H. E. Amino acid biosynthesis and its regulation. Annu. Rev. Biochem. 47, 532-606 (1978).

6 Ejim, L. J. et al. Inhibitors of bacterial cystathionine beta-lyase: leads for new antimicrobial agents and probes of enzyme structure and function. J. Med. Chem. 50, 755-764 (2007)

7 Mirza, I. A., Nazi, I., Korczynska, M., Wright, G. D. \& Berghuis, A. M. Crystal structure of homoserine transacetylase from Haemophilus influenzae reveals a new family of alpha/beta-hydrolases. Biochemistry 44, 15768-15773 (2005).

8 Nazi, l. et al. Role of homoserine transacetylase as a new target for antifungal agents. Antimicrob. Agents Chemother. 51, 1731-1736 (2007).

9 Nazi, I. \& Wright, G. D. Catalytic mechanism of fungal homoserine transacetylase. Biochemistry 44, 13560-13566 (2005).

10 Bareich, D. C., Nazi, I. \& Wright, G. D. Simultaneous in vitro assay of the first four enzymes in the fungal aspartate pathway identifies a new class of aspartate kinase inhibitor. Chem. Biol. 10, 967-973 (2003).

11 Bareich, D. C. \& Wright, G. D. Functionally important amino acids in Saccharomyces cerevisiae aspartate kinase. Biochem. Biophys. Res. Commun. 311, 597-603 (2003).

$12 \mathrm{Ejim}$, L. et al. New phenolic inhibitors of yeast homoserine dehydrogenase. Bioorg. Med. Chem. 12, 3825-3830 (2004).
13 Yamaguchi, M. et al. The mode of antifungal action of (S)2-amino-4-oxo-5-hydroxypentanoic acid, RI-331. J. Antibiot. 43, 411-416 (1990).

14 Yamaki, $\mathrm{H}$ et al. The mechanism of antifungal action of (S)-2-amino-4-oxo-5hydroxypentanoic acid, RI-331: the inhibition of homoserine dehydrogenase in Saccharomyces cerevisiae. Biochem. Biophys. Res. Commun. 168, 837-843 (1990).

15 Kingsbury, J. M. \& McCusker, J. H. Threonine biosynthetic genes are essential in Cryptococcus neoformans. Microbiology 154(Pt 9), 2767-2775 (2008).

16 Kingsbury, J. M. \& McCusker, J. H. Fungal homoserine kinase (thr1delta) mutants are attenuated in virulence and die rapidly upon threonine starvation and serum incubation. Eukaryot. Cell 9, 729-737 (2010).

17 Kingsbury, J. M. \& McCusker, J. H. Homoserine toxicity in Saccharomyces cerevisiae and Candida albicans homoserine kinase (thr1delta) mutants. Eukaryot. Cell 9, 717-728 (2010)

18 Born, T. L., Franklin, M. \& Blanchard, J. S. Enzyme-catalyzed acylation of homoserine: mechanistic characterization of the Haemophilus influenzae met2-encoded homoserine transacetylase. Biochemistry 39, 8556-8564 (2000).

19 Andersen, G. L., Beattie, G. A. \& Lindow, S. E. Molecular characterization and sequence of a methionine biosynthetic locus from Pseudomonas syringae. J. Bacteriol. 180, 4497-4507 (1998).

20 Picardeau, M., Bauby, H. \& Saint Girons, I. Genetic evidence for the existence of two pathways for the biosynthesis of methionine in the Leptospira spp. FEMS Microbiol. Lett. 225, 257-262 (2003).

21 Ruckert, C., Puhler, A. \& Kalinowski, J. Genome-wide analysis of the L-methionine biosynthetic pathway in Corynebacterium glutamicum by targeted gene deletion and homologous complementation. J. Biotechnol. 104, 213-228 (2003).

22 Fasman, G. D. Handbook of Biochemistry and Molecular Biology 3rd edn (CRC Press, Cleveland, $\mathrm{OH}, 1976)$.

23 De Pascale, G. \& Wright, G. D. Antibiotic resistance by enzyme inactivation: from mechanisms to solutions. Chembiochem 11, 1325-1334 (2010).

24 Romo, D. et al. Synthesis and inhibitory action on HMG-CoA synthase of racemic and optically active oxetan-2-ones (beta-lactones). Bioorg. Med. Chem. 6, 1255-1272 (1998).

25 Yang, H. W., Zhao, C. X. \& Romo, D. Studies of the tandem Mukaiyama aldol-lactonization (TMAL) reaction: a concise and highly diastereoselective route to beta-lactones applied to the total synthesis of the potent pancreatic lipase inhibitor, (-)-panclicin D. Tetrahedron 53, 16471-16488 (1997).

26 Tomoda, H., Kumagai, H., Tanaka, H. \& Omura, S. F-244 specifically inhibits 3-hydroxy-3-methylglutaryl coenzyme A synthase. Biochim. Biophys. Acta. 922, 351-356 (1987).

27 Umezawa, H. et al. Ebelactone, an inhibitor of esterase, produced by actinomycetes. J. Antibiot. 33, 1594-1596 (1980).

28 Uotani, K., Naganawa, H., Aoyagi, T. \& Umezawa, H. Biosynthetic studies of ebelactone A and B by 13 C NMR spectrometry. J. Antibiot. 35, 1670-1674 (1982).

29 Uotani, K., Naganawa, H., Kondo, S., Aoyagi, T. \& Umezawa, H. Structural studies on ebelactone $\mathrm{A}$ and $\mathrm{B}$, esterase inhibitors produced by actinomycetes. J. Antibiot. 35, 1495-1499 (1982).

30 Fleischmann, R. D. et al. Whole-genome random sequencing and assembly of Haemophilus influenzae Rd. Science 269, 496-512 (1995).

31 Cole, S. T. et al. Deciphering the biology of Mycobacterium tuberculosis from the complete genome sequence. Nature 393, 537-544 (1998).

32 Bourhy, P., Martel, A., Margarita, D., Saint Girons, I. \& Belfaiza, J. Homoserine 0 -acetyltransferase, involved in the Leptospira meyeri methionine biosynthetic pathway, is not feedback inhibited. J. Bacteriol. 179, 4396-4398 (1997).

33 Langin, T., Faugeron, G., Goyon, C., Nicolas, A. \& Rossignol, J. L. The MET2 gene of Saccharomyces cerevisiae: molecular cloning and nucleotide sequence. Gene 49, 283-293 (1986).

34 Turnidge, J. D. The pharmacodynamics of beta-lactams. Clin. Infect. Dis. 27, 10-22 (1998).

$35 \mathrm{Neu}$, H. C. \& Fu, K. P. Clavulanic acid, a novel inhibitor of beta-lactamases. Antimicrob. Agents Chemother. 14, 650-655 (1978).

36 Adlington, R. M. et al. Design, synthesis, and proposed active site binding analysis of monocyclic 2-azetidinone inhibitors of prostate specific antigen. J. Med. Chem. 44, 1491-1508 (2001).

37 Bonneau, P. R. et al. Inhibition of human cytomegalovirus protease by monocyclic $\beta$-lactam derivatives: kinetic characterization using a fluorescent probe. J. Am. Chem. Soc. 121, 2965-2973 (1999).

38 Borthwick, A. D. et al. Design and synthesis of monocyclic beta-lactams as mechanismbased inhibitors of human cytomegalovirus protease. Bioorg. Med. Chem. Lett. 8, 365-370 (1998).

39 Tomoda, H. et al. Synthesis of four chiral isomers of beta-lactone DU-6622 and inhibition of HMG-CoA synthase by the specific (2R,3R)-isomer. J. Org. Chem. 62, 2161-2165 (1997)

40 Tomoda, H. et al. Differential inhibition of HMG-CoA synthase and pancreatic lipase by the specific chiral isomers of beta-lactone DU-6622. Biochem. Biophys. Res. Commun. 265, 536-540 (1999).

41 Cooksey, J. P., Ford, R., Kocienski, P. J., Pelotier, B. \& Pons, J.- M. A synthesis of (-)ebelactones A and B. Tetrahedron 66, 6462-6467 (2010). 